\title{
Survival Analysis of Duration of Breastfeeding and Associated Factors of Early Cessation of Breastfeeding in Ethiopia
}

\author{
Melkamu Molla ${ }^{1, *}$ and Leakemariam Berhe ${ }^{2}$ \\ ${ }^{1}$ Department of Statistics, Jigjiga University, Ethiopia \\ ${ }^{2}$ Addis Ababa University, Ethiopia
}

\begin{abstract}
The purpose of this study was to assess the duration of breastfeeding among women of reproductive age in Ethiopia and to identify determinants associated with early cessation of breastfeeding. Data for the study were drawn from the Ethiopia Demographic and Health Survey 2005. The study included mothers of 9,066 children from nine regional states and two city administrations. The Kaplan-Meier and stratified Cox's hazard model were employed for the analysis of breastfeeding-related data. The Kaplan-Meier survival estimate showed that the probability of mothers who continue to breastfeeding was high $(97.3 \%)$ for the first month. The breastfeeding rates then declined to $92.5 \%$ at 6 months, $78.4 \%$ at 12 months, $37 \%$ at 24 months and $8.3 \%$ at 48 months. The mean and median duration of breastfeeding in Ethiopia were 25.64 and 24.00 months respectively. The stratified Cox regression analysis revealed that younger mothers, mothers who had lived in urban area, mothers having higher education, higher maternal parity, early pregnant and being a Muslim and protestant were significant determinants of early cessation of breastfeeding in Ethiopia. Then, we recommend that the breastfeeding-promotion programs in Ethiopia should give special attention to young mothers, those who lived in urban areas, mothers with higher education, those who have higher parity, those who have early pregnancy and who are Muslims and Protestants since these mothers tend to breastfeed their child for a relatively shorter period of time.
\end{abstract}

Keywords: Breastfeeding duration, Kaplan-Meier estimator, Determinants, Stratified- Cox regression model, Hazard-Ratio, Ethiopia.

\section{INTRODUCTION}

Breast milk is the most suitable food for human newborn and safest way of feeding infants for the first four to six months of life. It contains all types of nutrients required for an infant in right proportion and composition [1]. Breastfeeding has a major role to play in public health. It promotes health and prevents disease in both the short and long term, for both infant and mother. Breastfeeding plays a vital and influential role on the duration of amenorrhoea, child survival, and fertility, offering protection to an infant against early morbidity and mortality [2]. Short-term risks of not breastfeeding include an increased risk of postpartum haemorrhage while long-term effects may include a higher risk of osteoporosis and breast and ovarian cancers [2].

Infants who are properly breast-fed grow better and experience less sickness and fewer deaths than other infants who are not breastfed. Every day, as many as 4,000 infants and young children die worldwide because they are not breastfed [3]. According to [4], the death of children due to lack of breastfed is because their mothers are not empowered with adequate knowledge about breastfeeding and do not receive enough motivation and support.

*Address correspondence to these authors at the Department of Biostatistics, Jigjiga University, Ethiopia; Mob: +251920273369;

E-mail: melkamum2m@gmail.com
There are 9 million infant deaths a year with 4.5 million deaths of under-five in Sub-Saharan Africa. Up to 55 percent of infant deaths from diarrheal disease and acute respiratory infections may result from inappropriate feeding practices [5]. In Ethiopia in appropriate child feeding practices is commonly seen among severe acute malnutrition mothers which is major factor $(57 \%)$ for infant \& child mortality. Further, inadequate breastfeeding practices contribute to 70,000 infant deaths every year [6].

Longer and more frequent breastfeeding and maternal survival status ensure the survival of children [7]. Research shows that breast-feeding can save the lives of over 1,500,000 babies who die every year from diseases such as diarrhoea and pneumonia. Breastfed babies have stronger immune systems and are healthier than bottle-fed babies [4]. This anti-infective property of breast milk is substantial especially in countries with a moderate or high infant mortality rate. In such countries, artificially fed infants are at least 14 times more likely to die from diarrhoea and 4 times more likely to die from pneumonia than breastfed infants [8].

In addition to anti-infective property, breast milk also facilitates the establishment of a strong relationship between mother and infant. Moreover, it protects mothers from pre-menopausal breast cancer [8]. Another advantage is that it can prevent closely spaced 
births. If the mother fully breastfeeds for a longer duration, there is a delay for next pregnancy even if she does not use any contraceptive method. By delaying closely spaced births naturally, there will be a reduced risk of having a low-birth weight infant in the next pregnancy. It in turn leads to preventing infant morbidity and mortality and enhance child survival [9].

Realizing the great advantages of breast-feeding and the changing patterns of breast-feeding practice worldwide, [3] recommended that all infants should be exclusively breastfed for 4 to 6 months of age. Moreover, [4] has advocated breast-feeding as one of the strategies for "Child Survival" and exclusive breastfeeding as a best protective way for infants against infection and malnutrition. But, according to [10] report, only one in three Ethiopian children aged 4-5 months is exclusively breastfed with short median duration of 2.1 months and complementary foods are not introduced timely.

A large body of research supports an association between the socioeconomic status and the health and development of children [11-15]. Results of studies on early cessations of breastfeeding of children suggest that mothers who have higher education stop breastfeeding earlier than those with lower education [16-17]. Other factors that also relate to the duration of breastfeeding are present age of mothers, socioeconomic status and health service status [17-20]. But this concept has rarely been studied in relation to the duration of breastfeeding in the context of Ethiopia. In Ethiopia there is little research on the patterns of determinants of early termination of breastfeeding. The majority of them are focused on breastfeeding practice concentrated at town level in a region. Such studies miss an important point for policy makers as the conclusions from towns may not show the exact situation at national level including rural part of Ethiopia. Thus, this study attempts to assess the duration of breastfeeding among women of reproductive age in Ethiopia, and to identify socioeconomic, demographic and health care service factors associated with duration of breastfeeding in Ethiopia.

\section{DATA AND METHODOLOGY}

\section{Data}

The source of data for this study is the 2005 Ethiopian Demographic and Health Survey (EDHS) obtained from the Central Statistical Agency (CSA) of Ethiopia. The survey is the second major survey, following the 2000 EDHS survey, designed to provide estimates for the health and demographic variables of interest for the following domains: Ethiopia as a whole, urban and rural areas of Ethiopia (each as a separate domain), and all geographic areas (nine regions and two city administrations). The 2005 EDHS used a twostage stratified nationally representative sample of households for the data collection. A representative sample of approximately 14,500 households from 540 clusters was selected. The number of children at this level was 9,861 representing the number of live births born to the interviewed mothers in the period of five years preceding the date of the survey. Then, after a certain rearrangement and reorganization of the data mothers of 9,066 children with complete information were used as the data for this study.

\section{Methodology}

The response/dependent variable in this study is the duration of breastfeeding of the last child of the respondent calculated as the number of months that a child breastfeed. Hence, Survival analysis technique was used in analyzing time-to-event data (breastfeeding-related data).

The survival analysis technique adjusts for truncation bias by incorporating both complete and incomplete segments of histories in the analysis of breastfeeding-related data. The completed observations were those in which breastfeeding was stopped, and the exact duration of breastfeeding was known and the in-completed (Censored) observations were those in which the child was still being breastfed at the time of survey.

Bivariate and multivariable statistical techniques were used for studying the response variable (duration of breastfeeding) in relation to the explanatory variables. Descriptive statistics and the individual effects of Cox regression analysis for each variable (using univariable Cox's proportional hazard model) are given to provide a general overview of the covariates in the analysis. The Kaplan-Meier analysis is used in this study to estimate average duration of breastfeeding, the survival time (time of continuing breastfeeding) and to construct survival curves. The Kaplan-Meier estimator of the survival function at time $t$ is given by:

$$
\hat{S}(t)=\prod_{j=1}^{k}\left\{\frac{n_{j}-d_{j}}{n_{j}}\right\}
$$

for $\mathrm{t}_{(\mathrm{k})} \leq \mathrm{t}_{(\mathrm{k}+1)}, \mathrm{k}=1,2, \ldots, \mathrm{r}$, with $\hat{S}(\mathrm{t})=1$ for $\mathrm{t}<\mathrm{t}_{(1)}$. 
The net contribution of socio-demographic variables (factors) on experience to an event (termination of breastfeeding) was assessed by using the Cox proportional hazard model, which combines the features of life table and regression. Cox's proportional hazard model is a powerful tool for analyzing time-toevent data [21]. The Cox hazard function is specified as a function of time and the covariates:

$h(t, \boldsymbol{X}, \boldsymbol{\beta})=h_{0}(t) \cdot \exp \left(\boldsymbol{\beta}^{\prime} \boldsymbol{X}\right)$

where, $h_{0}(t)$ is the baseline hazard function that characterizes how the hazard function changes as a function of survival time, $h(t, \boldsymbol{X}, \boldsymbol{\beta})$ represents the hazard function at time $\mathrm{t}$ with covariates $\boldsymbol{X}=\left(X_{1}, X_{2}, \ldots, X_{p}\right)^{\prime} \boldsymbol{\beta}=\left(\beta_{1}, \beta_{2}, \ldots, \beta_{p}\right)^{\prime} \quad$ is a column vector of $p$ regression parameters, $\exp \left(\boldsymbol{\beta}^{\prime} \boldsymbol{X}\right)$ characterizes how the hazard function changes as a function of subject covariates.

$t$ is the event time (time of stop breastfeeding).

The regression coefficients of the model were estimated using maximum likelihood method. The study used Breslow's approximation to handle tied observation. $R_{P}^{2}$ partial likelihood ratio-test, Waldtest and the score-test were used to check the overall goodness of fit and the significance of the coefficients. Plots of the scaled Schoenfeld residuals (and a lowess smoother) as a function of log-time and the GrambschTherneau test of none-proportionality were also used to assess proportionality assumption. The assumption of linearity was checked by using the plot of martingale residuals.

To determine factors affecting the duration of breastfeeding, we also used Stratified Cox's Proportional Hazard Model [22]. When the assumption of proportionality (that the hazard of stop breastfeeding at any given time for a child in one group is proportional to the hazard at that time for a child in the other group) is violated, the simple Cox regression model is invalid and more complicated analyses such as the stratified Cox regression model or the extended Cox regression model is required. The stratified Cox regression model is a modification of the Cox regression model by the stratification of a covariate that does not satisfy the proportional hazards assumption. Covariates that are assumed to satisfy the proportional hazards assumption are included in the model, whereas the predictor being stratified is not included [22].

Let $k$ covariates fail to satisfy the proportional hazards assumption, and $p$ covariates satisfy proportional hazards assumption. The covariates not satisfying the proportional hazards assumption are denoted by $Z_{1}, Z_{2}, \ldots, Z_{k}$ and the covariates satisfying the proportional hazards assumption are denoted by $X_{1}, X_{2}, \ldots, X_{p}$. To form the stratified Cox regression model, a new variable is defined from $z$ variables and denoted by $z^{*}$. The stratification variable $z^{*}$ has $k^{*}$ categories, where $k^{*}$ is the total number of combinations (strata) formed after categorizing each of $z$ 's. The stratified cox regression model is defined (Klein et al., 1997) as:

$$
h_{g}(t, \boldsymbol{X}, \boldsymbol{\beta})=h_{0 g}(t) \exp \left(\boldsymbol{\beta}^{\prime} \boldsymbol{X}\right)
$$

where the subscript $g$ represents the strata. The strata are the different categorizations of the stratum variable. The variable $z^{*}$ is not implicitly included in the model, whereas the $\mathbf{x}$ 's which are assumed to satisfy the proportional hazards assumption are included in the model. The baseline hazard function, $h_{0 g}(t)$, is different for each stratum. However, the coefficient vector $\boldsymbol{\beta}$ is the same for each stratum. Since the coefficients of the $x$ 's are the same for each stratum, the hazard ratios are same for each stratum.

\section{STATISTICAL DATA ANALYSIS AND RESULTS}

\section{Descriptive Survival Analyses}

The major socioeconomic, demographic and health care service background characteristics of the respondents and their children are presented in Table 1 below.

The study included 9,066 mothers, who gave birth during the five years preceding the date of the survey; with $47.2 \%$ of children were still breastfeeding and the remaining $52.8 \%$ were completely stop breastfeeding at the time of the survey. From Table 1 below; of the total of 9,066 children included, $49.2 \%$ were females, $86.4 \%$ were lived in rural part of Ethiopia. With regard to educational attainment, about $77.4 \%$ of mothers had no education while $15.5 \%$ of mothers had primary education and the remaining $7.1 \%$ mothers had attained secondary and higher education level.

The mean and median duration of breastfeeding in Ethiopia for surviving children are 25.64 and 24.00 respectively. The average duration of breastfeeding was 22.63 months for urban mothers compared to 26.01 months for those who were lived in rural part of Ethiopia. The highest mean duration of breastfeeding was 31.04 months for Amhara region mothers; for Gambela region mothers mean duration of 
Table 1: Summary of some Important Demographic, Socio-Economic and Health Care Service Characteristics of Mother and her Child in Ethiopia

\begin{tabular}{|c|c|c|c|c|}
\hline Covariates & Category & Censored & Event/stop breastfeeding (\%) & Total \\
\hline Age of Mother & $\begin{array}{l}15-24 \\
25-29 \\
30-34 \\
35-49\end{array}$ & $\begin{array}{c}1260 \\
1232 \\
823 \\
963\end{array}$ & $\begin{array}{c}1101(23.0) \\
1414(29.5) \\
982(20.5) \\
1291(27.0)\end{array}$ & $\begin{array}{l}2361 \\
2646 \\
1805 \\
2254\end{array}$ \\
\hline Sex of child & $\begin{array}{c}\text { Male } \\
\text { Female }\end{array}$ & $\begin{array}{l}2175 \\
2103\end{array}$ & $\begin{array}{l}2435(50.9) \\
2353(49.1)\end{array}$ & $\begin{array}{l}4610 \\
4456\end{array}$ \\
\hline Parity & $\begin{array}{c}1 \\
2 \\
3-5 \\
>=6\end{array}$ & $\begin{array}{c}727 \\
711 \\
1653 \\
1187\end{array}$ & $\begin{array}{c}376(7.9) \\
846(17.7) \\
1966(41.1) \\
1600(33.4)\end{array}$ & $\begin{array}{l}1103 \\
1557 \\
3619 \\
2787\end{array}$ \\
\hline Currently pregnant & $\begin{array}{l}\text { No } \\
\text { Yes }\end{array}$ & $\begin{array}{c}4175 \\
103\end{array}$ & $\begin{array}{c}3958(82.7) \\
830(17.3)\end{array}$ & $\begin{array}{c}8133 \\
933\end{array}$ \\
\hline Mothers education & $\begin{array}{c}\text { No education } \\
\text { Primary } \\
\text { Secondary \& higher }\end{array}$ & $\begin{array}{c}3322 \\
674 \\
282\end{array}$ & $\begin{array}{c}3691(77.1) \\
732(15.3) \\
365(7.6)\end{array}$ & $\begin{array}{c}7013 \\
1406 \\
647\end{array}$ \\
\hline Fathers education & $\begin{array}{c}\text { No education } \\
\text { Primary } \\
\text { Secondary \& higher }\end{array}$ & $\begin{array}{l}2554 \\
1127 \\
597\end{array}$ & $\begin{array}{c}2839(59.3) \\
1247(26.0) \\
702(14.7)\end{array}$ & $\begin{array}{l}5393 \\
2374 \\
1299\end{array}$ \\
\hline $\begin{array}{c}\text { Current work status of } \\
\text { mothers }\end{array}$ & $\begin{array}{c}\text { Not working } \\
\text { Working }\end{array}$ & $\begin{array}{c}3339 \\
939 \\
\end{array}$ & $\begin{array}{l}3699(77.3) \\
1089(22.7) \\
\end{array}$ & $\begin{array}{l}7038 \\
2028 \\
\end{array}$ \\
\hline $\begin{array}{l}\text { household economic } \\
\text { status(wealth index) }\end{array}$ & $\begin{array}{l}\text { Poor } \\
\text { Middle } \\
\text { Rich }\end{array}$ & $\begin{array}{c}1880 \\
826 \\
1572 \\
\end{array}$ & $\begin{array}{c}2107(44.0) \\
888(18.5) \\
1793(37.4) \\
\end{array}$ & $\begin{array}{l}3987 \\
1714 \\
3365\end{array}$ \\
\hline Place of residence & $\begin{array}{l}\text { Urban } \\
\text { Rural }\end{array}$ & $\begin{array}{c}524 \\
3754\end{array}$ & $\begin{array}{c}708(14.8) \\
4080(85.2)\end{array}$ & $\begin{array}{l}1232 \\
7834\end{array}$ \\
\hline Region & $\begin{array}{c}\text { Tigray } \\
\text { Affar } \\
\text { Amhara } \\
\text { Oromia } \\
\text { Somali } \\
\text { Ben-Gumuz } \\
\text { SNNP } \\
\text { Gambela } \\
\text { Harari } \\
\text { Addis Ababa } \\
\text { Dire Dawa }\end{array}$ & $\begin{array}{l}403 \\
246 \\
768 \\
802 \\
235 \\
273 \\
821 \\
234 \\
206 \\
140 \\
150\end{array}$ & $\begin{array}{c}535(11.2) \\
286(6.0) \\
613(12.8) \\
965(20.2) \\
363(7.6) \\
282(5.9) \\
804(16.8) \\
230(4.8) \\
278(5.8) \\
185(3.9) \\
247(5.2)\end{array}$ & $\begin{array}{c}938 \\
532 \\
1381 \\
1768 \\
598 \\
555 \\
1625 \\
464 \\
484 \\
325 \\
397\end{array}$ \\
\hline Religion & $\begin{array}{l}\text { Orthodox } \\
\text { Protestant } \\
\text { Muslim } \\
\text { Other }\end{array}$ & $\begin{array}{c}1821 \\
798 \\
1526 \\
133\end{array}$ & $\begin{array}{c}1805(37.7) \\
824(17.2) \\
2017(42.1) \\
142(3.0)\end{array}$ & $\begin{array}{c}3626 \\
1622 \\
3543 \\
275\end{array}$ \\
\hline Place of delivery & $\begin{array}{c}\text { Home } \\
\text { Health facility }\end{array}$ & $\begin{array}{c}3849 \\
429\end{array}$ & $\begin{array}{c}4297(89.7) \\
491(10.3)\end{array}$ & $\begin{array}{c}8146 \\
920\end{array}$ \\
\hline Delivery status & $\begin{array}{l}\text { Normally delivered } \\
\text { By caesarean section }\end{array}$ & $\begin{array}{c}4203 \\
75\end{array}$ & $\begin{array}{c}4709(98.4) \\
79(1.6)\end{array}$ & $\begin{array}{c}8912 \\
154\end{array}$ \\
\hline
\end{tabular}

breastfeeding was 29.15 months. This decreased to 20.64 and 18.69 months for Harari and Dire Dawa mothers. Tables 2 and $\mathbf{3}$ show that mean and median survival time of breastfeeding and mean duration of breastfeeding by different socio-demographic characteristics based on Kaplan-Meier technique respectively.

The graph of the estimate of overall Kaplan-Meier survival curve, Figure 1, showed that the probability of 
Table 2: Mean and Median Survival Time of Breastfeeding and their $95 \% \mathrm{Cl} \& \mathrm{SE}$

\begin{tabular}{|c|c|c|c|c|c|c|c|}
\hline \multicolumn{4}{|c|}{ Mean } & \multicolumn{4}{|c|}{ Median } \\
\hline \multirow[t]{2}{*}{ Estimate } & \multirow[t]{2}{*}{ Std. Er. } & \multicolumn{2}{|c|}{ 95\% Confidence Interval } & \multirow[t]{2}{*}{ Estimate } & \multirow[t]{2}{*}{ Std. Er. } & \multicolumn{2}{|c|}{ 95\% Confidence Interval } \\
\hline & & Lower Bound & Upper Bound & & & Lower Bound & Upper Bound \\
\hline 25.64 & 0.206 & 25.232 & 26.04 & 24.0 & 0.027 & 23.948 & 24.052 \\
\hline
\end{tabular}

Table 3: Mean Duration of Breastfeeding and $95 \% \mathrm{Cl}$ by Different Demographic, Socioeconomic and Health Care Service Characteristics Based on Kaplan-Meier Technique

\begin{tabular}{|c|c|c|c|c|}
\hline \multirow{2}{*}{ Characteristics } & \multirow{2}{*}{ Category } & \multirow{2}{*}{ Mean Duration of Brf. } & \multicolumn{2}{|c|}{$95 \%$ Confidence interval } \\
\hline & & & Lower Bound & Upper Bound \\
\hline Current age of Mothers & $\begin{array}{l}15-24 \\
25-29 \\
30-34 \\
35-49\end{array}$ & $\begin{array}{l}24.465 \\
24.951 \\
25.684 \\
26.869\end{array}$ & $\begin{array}{l}23.619 \\
24.249 \\
24.818 \\
26.088\end{array}$ & $\begin{array}{c}25.311 \\
25.653 \\
26.551 \\
27.65\end{array}$ \\
\hline Region & $\begin{array}{c}\text { Tigray } \\
\text { Affar } \\
\text { Amhara } \\
\text { Oromia } \\
\text { Somali } \\
\text { Ben-Gumuz } \\
\text { SNNP } \\
\text { Gambela } \\
\text { Harari } \\
\text { Addis Abab } \\
\text { Dire Dawa }\end{array}$ & $\begin{array}{l}24.283 \\
23.617 \\
31.039 \\
23.983 \\
22.013 \\
26.006 \\
27.272 \\
29.153 \\
20.635 \\
23.453 \\
18.687\end{array}$ & $\begin{array}{l}23.582 \\
21.961 \\
29.886 \\
23.152 \\
20.514 \\
24.533 \\
26.305 \\
27.213 \\
19.366 \\
21.609 \\
17.296\end{array}$ & $\begin{array}{l}24.984 \\
25.273 \\
32.191 \\
24.814 \\
23.511 \\
27.479 \\
28.238 \\
31.094 \\
21.905 \\
25.297 \\
20.078\end{array}$ \\
\hline place of residence & $\begin{array}{l}\text { Urban } \\
\text { Rural }\end{array}$ & $\begin{array}{l}22.633 \\
26.068\end{array}$ & $\begin{array}{l}21.724 \\
25.629\end{array}$ & $\begin{array}{l}23.543 \\
26.508\end{array}$ \\
\hline Mothers' educational level & $\begin{array}{c}\text { No education } \\
\text { Primary } \\
\text { secondary \&higher }\end{array}$ & $\begin{array}{c}25.948 \\
25.151 \\
22.94\end{array}$ & $\begin{array}{l}25.478 \\
24.261 \\
21.612 \\
\end{array}$ & $\begin{array}{l}26.417 \\
26.041 \\
24.268 \\
\end{array}$ \\
\hline Wealth index & $\begin{array}{l}\text { Poor } \\
\text { Middle } \\
\text { Rich }\end{array}$ & $\begin{array}{c}25.713 \\
25.7 \\
25.324\end{array}$ & $\begin{array}{c}25.11 \\
24.775 \\
24.682\end{array}$ & $\begin{array}{l}26.315 \\
26.624 \\
25.966\end{array}$ \\
\hline Sex of child & $\begin{array}{l}\text { Male } \\
\text { Female }\end{array}$ & $\begin{array}{l}25.338 \\
25.843\end{array}$ & $\begin{array}{l}24.784 \\
25.267\end{array}$ & $\begin{array}{l}25.892 \\
26.418\end{array}$ \\
\hline parity & $\begin{array}{c}1 \\
2 \\
3-5 \\
>=6\end{array}$ & $\begin{array}{c}28.53 \\
24.143 \\
25.443 \\
25.434\end{array}$ & $\begin{array}{c}27.2 \\
23.237 \\
24.841 \\
24.728\end{array}$ & $\begin{array}{c}29.86 \\
25.049 \\
26.045 \\
26.14\end{array}$ \\
\hline Currently pregnant & $\begin{array}{l}\text { No } \\
\text { Yes }\end{array}$ & $\begin{array}{l}26.589 \\
20.164\end{array}$ & $\begin{array}{l}26.133 \\
19.385\end{array}$ & $\begin{array}{l}27.046 \\
20.943\end{array}$ \\
\hline Place of delivery & $\begin{array}{l}\text { At Home } \\
\text { At Health facility }\end{array}$ & $\begin{array}{l}25.799 \\
24.135\end{array}$ & $\begin{array}{l}25.373 \\
22.892\end{array}$ & $\begin{array}{l}26.225 \\
25.378\end{array}$ \\
\hline Delivery status & $\begin{array}{l}\text { By caesarean section } \\
\text { Normally delivered }\end{array}$ & $\begin{array}{l}25.664 \\
23.987\end{array}$ & $\begin{array}{l}25.257 \\
20.688\end{array}$ & $\begin{array}{l}26.071 \\
27.287\end{array}$ \\
\hline Fathers' educational level & $\begin{array}{c}\text { No education } \\
\text { Primary } \\
\text { secondary \&higher }\end{array}$ & $\begin{array}{l}26.322 \\
24.467 \\
24.388\end{array}$ & $\begin{array}{l}25.775 \\
23.763 \\
23.498\end{array}$ & $\begin{array}{l}26.869 \\
25.172 \\
25.279\end{array}$ \\
\hline current employ -ment status & $\begin{array}{l}\text { Not working } \\
\text { working }\end{array}$ & $\begin{array}{l}25.439 \\
26.151\end{array}$ & $\begin{array}{l}24.978 \\
25.331\end{array}$ & $\begin{array}{c}25.9 \\
26.971\end{array}$ \\
\hline Religion & $\begin{array}{l}\text { Orthodox } \\
\text { Protestant } \\
\text { Muslim } \\
\text { Other }\end{array}$ & $\begin{array}{l}27.769 \\
26.531 \\
22.558 \\
28.985\end{array}$ & $\begin{array}{l}27.132 \\
25.575 \\
21.953 \\
26.666\end{array}$ & $\begin{array}{l}28.406 \\
27.487 \\
23.164 \\
31.304\end{array}$ \\
\hline
\end{tabular}




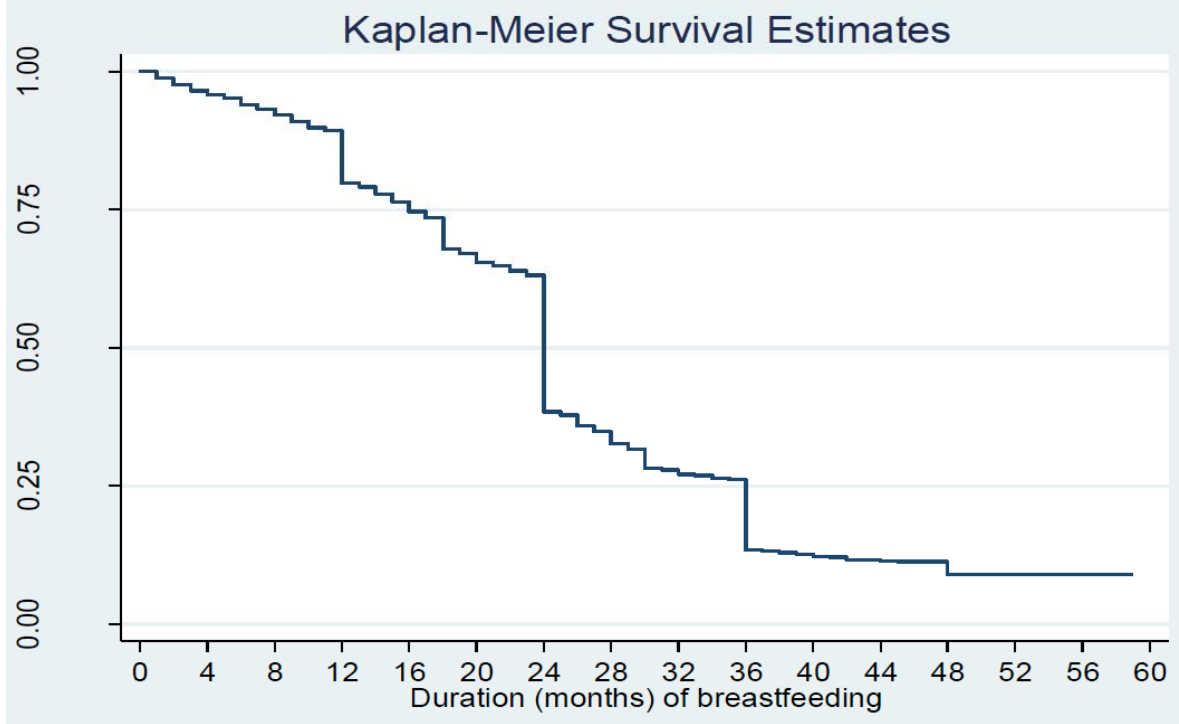

Figure 1: The plot of the overall estimate of Kaplan-Meier survivor function for women who were continuing breastfeeding at different durations (months) of breastfeeding, Ethiopia.

Table 4: The Reduced Proportional Hazards Model with Estimated Values of the Coefficients, Hazard Ratios, 95\% CI for the Hazard Ratio and P-Values of the Predictors

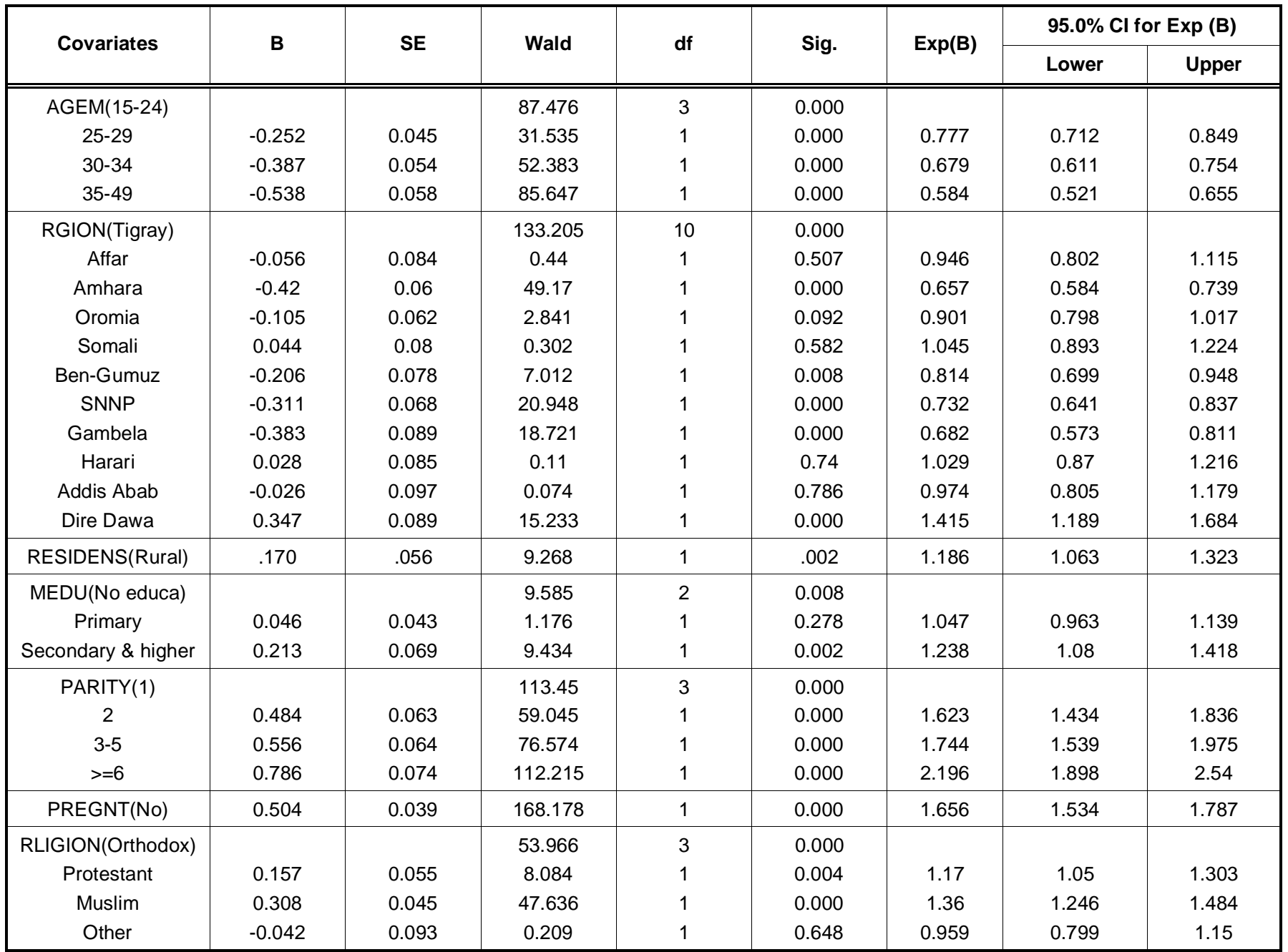

The reference categories are those indicated in brackets. 
mothers who continued to breastfeeding is high in the first months, which relatively decreases as follow up time (months of life of a child) increases. During the first month of life, the maximum (97.3\%) probability of survival (continuing breastfeeding) was observed with a standard error of 0.0017 , at 12 months of life the probability of continuing breastfeeding of a child is $78.4 \%$ with a standard error of 0.0048 , at 24 months of life the probability of continuing breastfeeding of a child is $37 \%$ with a standard error of 0.0065 and at 48 months of life the probability of continuing breastfeeding of a child is $8.3 \%$ with a standard error of 0.0063 for the follow-up period of time.

\section{Cox Proportional Hazard Regression Analysis}

Cox proportional hazard regression analysis was performed to identify the effect of each explanatory variable on breastfeeding duration. As can be seen in Table 4 below, the Cox proportional hazard regression analysis identified seven factors, which are age of mother, region, place of residence, mothers' educational level, parity, current pregnancy and religion, as a significant factors. The variables current employment status of mothers, place of delivery, delivery status and fathers' educational level are excluded from the model since they are not statistically significant factors based on the data.
As we have seen in the above Table 4, the predictor region is significant factor (with $\mathrm{P}$-value $=0.000 \ldots$ ). But the proportional hazards assumption is not satisfied for the covariate region. Stratification enables us to control for the effect of such a variable in a Cox model without making this assumption. The stratified Cox regression model is a modification of the Cox regression model by the stratification of a covariate that does not satisfy the proportional hazards assumption. Table 5 presents the results of the final proportional hazards model stratified by predictor region for the duration of breastfeeding and found that age of mother, place of residence, mothers' educational level, parity, current pregnancy and religion were statistically significant.

\section{DISCUSSION}

Based on the above Table 5, In this study, the covariates current age of mothers, place of residence, mothers' education, parity, current pregnancy, religion, and the stratified variable region were significantly affect the termination of breastfeeding in Ethiopia.

Mother's age at birth had a positive association with duration of breastfeeding. The risk of cessation of breastfeeding increased with increasing maternal education. Women with more than 35 years of age had

Table 5: Result of the Final Stratified Cox's Proportional Hazard Model Estimates of Relative Risk of SocioDemographic Characteristics on Cessation of Breastfeeding

\begin{tabular}{|c|c|c|c|c|c|c|c|c|}
\hline \multirow{2}{*}{ Covariates } & \multirow{2}{*}{ B } & \multirow{2}{*}{ SE } & \multirow{2}{*}{ Wald } & \multirow{2}{*}{ df } & \multirow{2}{*}{ Sig. } & \multirow{2}{*}{$\operatorname{Exp}(B)$} & \multicolumn{2}{|c|}{$95.0 \% \mathrm{Cl}$ for $\operatorname{Exp}(\mathrm{B})$} \\
\hline & & & & & & & Lower & Upper \\
\hline AGEM(15-24) & & & 93.564 & 3 & 0.000 & & & \\
\hline $30-34$ & -0.394 & 0.053 & 54.354 & 1 & 0.000 & 0.674 & 0.607 & 0.749 \\
\hline $35-49$ & -0.559 & 0.058 & 92.046 & 1 & 0.000 & 0.572 & 0.51 & 0.641 \\
\hline Primary & 0.06 & 0.043 & 1.938 & 1 & 0.164 & 1.061 & 0.976 & 1.154 \\
\hline Secondary \& higher & 0.225 & 0.07 & 10.415 & 1 & 0.001 & 1.252 & 1.092 & 1.436 \\
\hline $\operatorname{PARITY}(1)$ & & & 116.382 & 3 & 0.000 & & & \\
\hline 2 & 0.477 & 0.063 & 57.258 & 1 & 0.000 & 1.612 & 1.424 & 1.824 \\
\hline RLIGION(Orthodox) & & & 54.183 & 3 & 0.000 & & & \\
\hline Protestant & 0.157 & 0.055 & 8.126 & 1 & 0.004 & 1.171 & 1.05 & 1.304 \\
\hline Muslim & 0.313 & 0.045 & 48.736 & 1 & 0.000 & 1.367 & 1.252 & 1.492 \\
\hline Other & -0.025 & 0.093 & 0.074 & 1 & 0.785 & 0.975 & 0.813 & 1.17 \\
\hline
\end{tabular}

The reference categories are those indicated in brackets. 
lower risk of stopping breastfeeding than younger ages. Some other studies showed that older women are associated with longer duration of breastfeeding [1617, 23-24].

The estimated relative risk (hazard ratio) of cessation of breastfeeding for urban women as compared to rural women is $1.189(95 \% \mathrm{Cl}$ : $1.065-$ 1.326). This indicates that women who are lived in urban area were $19 \%$ more likely to terminate breastfeeding than the women in rural area. This implies that urban mothers breastfed their children for a relatively-shorter duration than the rural Mothers did. This finding is consistent with [17, 20]. The 95\% confidence interval also suggests that the risk of early terminating of breastfeeding for urban women could be as low as 1.065 and as high as 1.326 .

The other key determinant of the decline of breastfeeding in Ethiopia is the increasing level of education of mothers. Mothers who had completed secondary and higher education had 1.25 times more likely to stop breastfeeding than uneducated mothers (95\% Cl: 1.09-1.44). A similar trend that higher education is associated with shorter duration of breastfeeding was also observed in some other studies $[16-17,20,25]$.

The result of this study also suggested that an increase in parity is associated with an increase in probability of terminating breastfeeding. Mothers of 2 , $3-5$ and 6 or more parity were $1.61,1.75$ and 2.23 more likely to terminate breastfeeding than mothers with single parity. Some other studies observed that higher parity of mother is associated with shorter duration of breastfeeding (as the parity size increased, duration of breastfeeding becomes lower) [17, 25-27]. But in contrast, some other studies revealed that a positive relationship between parity and duration of breastfeeding (as the parity size increased, duration of breastfeeding becomes higher) [28-29].

Pregnancy has a significant negative association with duration of breastfeeding. The risk of cessation of breastfeeding increased with pregnant women as compared to not pregnant women. Pregnant women were $63 \%$ more likely to terminate breastfeeding early than not pregnant women. The result of this study is consistent with [30] that mothers discontinue breastfeeding as soon as they know that they are pregnant. It is because of a common belief that breast milk of pregnant women can rot and cause disease in children [31] revealed that a subsequent pregnancy is the most important covariate of breast-feeding behaviour. The start of a subsequent pregnancy is associated with a greatly increased hazard of weaning and introduction of supplemental food.

The hazards of terminating breastfeeding by Muslim mothers were higher compared to Orthodox mothers. Muslim mothers had 1.37 times more likelihood of stop breastfeeding than Orthodox mothers. The result of this study is consistent with [17] that the probability of terminating breastfeeding by Muslim mothers was higher compared to non-Muslim mothers (Hindu, Christian, and Buddhist). In this study protestant mothers also had $17 \%$ more likely to terminate breastfeeding than Orthodox mothers.

\section{CONCLUSION AND RECOMMENDATION}

This study was intended to identify socio-economic, demographic and health care service determinants of early cessation of breastfeeding in Ethiopia based on 2005 EDHS data. Thirteen covariates were selected for the study and 13 uni-variable Cox Proportional Hazards regression Model were developed to assess the relation between duration of breastfeeding status and the selected variables. Based on the results, the multivariable Cox Proportional Hazards regression Model of duration of breastfeeding status was employed to select the most important determinants of early cessation of breastfeeding.

The mean and median duration of breastfeeding in Ethiopia for surviving children are 25.64 and 24.00 months respectively. The results of Cox's regression model stratified by region showed that current age of mother, place of residence, mother education, parity, current pregnancy and religion are the most important determinants of early cessation of breastfeeding. Specifically the study revealed that the duration of breastfeeding to be shorter among younger age mothers, urban mothers, mothers' with higher education, having higher parity, currently pregnant mothers, Muslim and protestant mothers. But variables sex of child, wealth index, current employment status of mothers, place of delivery, delivery status and fathers' educational level were not statistically significant. Therefore, in order to protect, promote and support breastfeeding and encouraging mothers to breastfeed longer, we recommend that the breastfeedingpromotion programs, policies, plans and any other efforts in Ethiopia should give special attention to younger age mothers, those who lived in urban areas, mothers' with higher education, those who have higher 
parity, those who have early pregnancy and those who are Muslim and protestant since these mothers tend to breastfeed their children for a relatively-shorter period of time.

\section{REFERENCES}

[1] Aryal TR. Some techniques to estimate child mortality in Nepal. J Inst Sci Technol 2004; 13: 48-61.

[2] Heinig MJ, Dewey KG. Health advantages of breastfeeding for mothers: A critical review. Nutr Res Rev 1997; 10: 35-56. http://dx.doi.org/10.1079/NRR19970004

[3] UNICEF / WHO. Protecting, promoting and supporting breastfeeding: The special role of maternity services. Joint WHO / UNICEF Statement 2001; Geneva, WHO.

[4] UNICEF. World breastfeeding week: Protect breast-feeding. Making the Code Work 1994.

[5] Nelson. Text book of Paediatrics. $15^{\text {th }}$ ed. USA; 1996.

[6] Sheleme $\mathrm{H}$. Assessment of knowledge, attitude and intention to breastfeed among pregnant women following ANC in Addis Ababa, Ethiopia. Unpublished M.Sc. thesis in AAU 2011.

[7] Ronsmans C, Chowdhury M, Dasgupta S, Ahmed A, Koblinsky M. Effect of parent's death on child survival in rural Bangladesh: A cohort study 2010; 37: 24-31.

[8] Lucas A, Morley R, Cole TJ, Lister G, Leeson-payne C. Breast milk and subsequent intelligence in children born preterm. Lancet 1992; 339: 261-4. http://dx.doi.org/10.1016/0140-6736(92)91329-7

[9] Shah $\mathrm{IH}$, Khanna J. Breastfeeding, infant health and child survival in the Asia-Pacific context. Asia- Pacific population Journal 1990; 5(1): 25-44.

[10] Ethiopia Demographic and Health Survey. Central Statistical Authority, Addis Ababa 2005.

[11] Halldorsson M, Kunst AE, Kohler L, Mackenbach JP. Socioeconomic inequalities in the health of children and adolescents: A comparative study of the five nordic countries. Eur J Public Health 2000; 10: 281-8. http://dx.doi.org/10.1093/eurpub/10.4.281

[12] Hjern A, Bremberg S. Social etiology of violent deaths in Swedish children and youth. J Epidemiol Commun Health 2002; 56: 688-92.

http://dx.doi.org/10.1136/jech.56.9.688

[13] Fairley L, Leyland $\mathrm{AH}$. Social class inequalities in perinatal outcomes: Scotland 1980-2000. J Epidemiol Community Health 2006; 60: 31-36.

http://dx.doi.org/10.1136/jech.2005.038380

[14] Rueden U, Gosch A, Rajmil L, Bisegger C, Ravens-Sieberer $U$. Socioeconomic determinants of health related quality of life in childhood and adolescence: Results from a European study. J Epidemiol Community Health 2006; 60(2): 130-5. http://dx.doi.org/10.1136/jech.2005.039792
[15] Tin O. Factors influencing breastfeeding and weaning practices among mothers of children under 3 years of age in Ratchaburi Province of Thailand. Mahidol University 1995.

[16] Aryal TR. Breastfeeding in Nepal: Patterns and determinants. JNep Med Assoc 2007; 46: 13-19.

[17] Akter S, Rahman M. Duration of breastfeeding and its correlates in Bangladesh. Bangladesh J Health Popul Nutr 2010; 28: 595-601.

http://dx.doi.org/10.3329/jhpn.v28i6.6608

[18] Lande B, Andersen LF, Baerug A, et al. Infant feeding practices and associated factors in the first six months of life: The Norwegian infant nutrition survey. Acta Paediatr 2003; 92:152-61. http://dx.doi.org/10.1111/j.1651-2227.2003.tb00519.x

[19] Nolan L, Goel V. Socio-demographic factors related to breastfeeding in Ontario: Results from the Ontario health survey. Can J Public Health 1995; 86:309-12.

[20] Giashuddin, Kabir. Breastfeeding duration in Bangladesh and factors associated with it. Indian Journal of Community Medicine 2003; 28(1).

[21] Cox DR. Regression models and life tables. Journal of the Royal Statistical Society: Series B (Methodological) 1972; 34(2): 187-220.

[22] Klein, John $P$, Moeschberger ML. Survival analysis techniques for censored and truncated data. New York, Springer 1997.

[23] Liu, Qiao, Fenglian Xu, Zhang, Wang, Binns. Factors associated with breastfeeding duration: A 30-month cohort study in Northwest China. J Hum Lact 2013; 29: 253. http://dx.doi.org/10.1177/0890334413477240

[24] Islam, Yadava, Alam. Differentials and determinants of the duration of breastfeeding in Bangladesh. Proc Pakistan Acad Sci 2006; 43: 1-14

[25] Sakyi Y, Takyi BK. Socio-demographic correlates of breast feeding in Ghana. 1991; 63(3): 389-402.

[26] Abada, Trovato, Lalu. Determinants of breastfeeding in the Philippines: a survival Analysis. Social Science and Medicine 2001; 52: 71-81. http://dx.doi.org/10.1016/S0277-9536(00)00123-4

[27] Adenusi O. Socio-demographic factors influencing breastfeeding duration and its effect on subsequent fertility in Nigeria. Population and Family Planning Research, Mahidol University, 1993.

[28] Iskandar MB, Costello C, Nasution Y. Initiation and duration of breast -feeding in Indonesia. Asia- Pacific Population Journal 1990; 5: 89-112.

[29] Mannan HR, and Islam MN. Breast feeding in bangladesh: Patterns and impact on fertility. Asia-Pacific Population Journal 1995; 10(4): 23-37.

[30] Bohler E, Ingstad B. The struggle of weaning: Factors determining breastfeeding duration in East Bhutan. Social Science and Medicine 1996; 43(12): 105-15. http://dx.doi.org/10.1016/S0277-9536(96)00086-X

[31] Ping T. Breast-feeding patterns and correlates in Shaanxi, China. Asia-Pacific Population Journal 1990; 5(1): 57-70. 